\title{
Fuentes documentales para un esbozo del arte sartorial: sastres de príncipes, reyes y nobles en la Corona de Castilla en los inicios de la Modernidad
}

\section{Documentary sources for an outline of sartorial art: tailors to princes, kings and nobles in the Court of Castile at the beginning of Modernity}

\author{
Alicia MARChANT RIVERA \\ Universidad de Málaga \\ amr@uma.es
}

Fecha de recepción: 08-06-2018

Fecha de aceptación: 18-07-2018

\section{RESUMEN}

Con el presente trabajo se pretende, sobre el soporte bibliográfico que registra la trayectoria del gremio sartorial, aportar un enfoque inédito proporcionado por las fuentes archivísticas y documentales para la época: la identificación, relación y análisis de la función ejercida por los sastres de los reyes y de aquellos vinculados al estamento nobiliario en la horquilla cronológica seleccionada, comprendida entre los años 1450 y 1615, fecha del primer y último documento trabajados en este sentido. Esta línea de investigación nos permitirá descubrir desde individuos con deseos de medrar en la escala social, como los sastres andantes y estantes en corte, hasta un subgrupo más consolidado marcado por la continua insatisfacción de las deudas por parte de la nobleza. Secciones archivísticas como el Registro General del Sello, Cámara de Castilla, Registro de Ejecutorias o Consejo de Estado, pertenecientes a variados archivos estatales españoles, nos servirán para proporcionar una nutrida nómina, en relación diacrónica, de los sastres vinculados a la Corona castellana en este periodo. Por otro lado, se destacará el proteccionismo regio hacia la figura de este artesano cercano a las élites de poder, ejemplificándolo en figuras concretas. Finalmente se apuntarán las posibilidades de la documentación analizada para conocer en profundidad, y de la mano de fuentes históricas primarias, aspectos de la historia del vestido regio y del de los empleados de la corte.

PALABRAS CLAVE: sastres, reyes, nobles, Corona de Castilla, 1450-1615 


\section{ABSTRACT}

The aim of the present work is, on the basis of the literature that records the trajectory of the sartorial profession, to offer a new approach provided by the archival and documentary sources of the time: the identification, relation and analysis of the function exerted by tailors to kings and to those linked to the nobility. This line of research will allow us to discover people ranging from individuals seeking to climb the social ladder, such as tailors living at the court, to a more consolidated subgroup marked by the continued non-payment of debts by the nobility. Archival sections such as the General Registry of the Seal, Chamber of Castile, Registry of Executives or Council of State, belonging to various Spanish state archives, will provide us with a long list, in diachronic terms, of the tailors linked to the Castilian Crown between 1450 and 1615, the dates of the first and last documents used for this purpose. Furthermore, I shall highlight royal protectionism vis-à-vis the figure of this craftsman close to the elites, offering specific examples. Finally, I shall refer to the potential of the documentation analysed to explore in depth, and via primary historical sources, aspects of the history of royal attire and that of court employees.

KEY WORDS: tailors, kings, nobles, Crown of Castile, 1450-1615

\section{INTRODUCCIÓN}

El presente estudio pretende dar a conocer, de primera mano, a través de los documentos de archivo, las coordenadas socio-económicas y profesionales vinculadas al gremio sartorial en el tránsito a la Modernidad y durante el primer siglo de consolidación de esta etapa histórica en la Corona de Castilla. Hasta ahora, la tripartición del objeto de estudio planteada se ha abordado aplicando el factor geográfico al amplio territorio peninsular, como se constatará en el segundo apartado del trabajo. También dando paso a parámetros tales como la importancia de la religiosidad colectiva y la legislación que reguló al gremio, así como las relaciones de género que se propiciaron en el mismo. Al margen de perspectivas añadidas como la huella social que pudieron labrar estos artesanos a tenor de la fortuna que les deparó la paremiología, o su actitud como colectivo frente a la acción del Tribunal de la Santa Inquisición.

Como añadidura a estos enfoques y contribución al ensanchamiento de las aportaciones científicas vertidas sobre esta agrupación gremial, la perspectiva en este estudio se sitúa en la identificación, relación y análisis de la función ejercida por los sastres reales o vinculados por el desempeño de su profesión al estamento nobiliario en la etapa señalada. Intentando de esta forma contribuir con el análisis e interpretación de fuentes documentales inéditas a la reconstrucción del universo histórico de este subgremio de artesanos, aquellos maestros que medraron y supieron codearse con lo más granado de la sociedad española de la época.

El análisis de las fuentes conservadas nos va a permitir documentar en el periodo comprendido entre 1450 y 1615, fecha del último documento trabajado: 3 sastres estantes en la Corte durante la segunda mitad del siglo XVI; 2 sastres andantes en Corte en la misma etapa cronológica; 5 sastres, afincados en variados puntos geográficos de la Corona de Castilla, que cosen a los nobles y a sus familias desde finales del siglo XV hasta las postrimerías del XVI y, finalmente, 8 sastres reales que trabajan para reyes, príncipes e infantas entre los años 1484 y 1587. Junto a ello recopilaremos la variopinta nomenclatura que se emplea en los documentos para referirse a estos personajes: sastres de SS. AA., sastres de los Reyes, sastre real, sastre del Príncipe o sastre de la Princesa de Gales, entre otras denominaciones. 


\section{METODOLOGÍA Y TRATAMIENTO BIBLIOGRÁFICO DEL GREMIO}

En la investigación histórica más reciente, el colectivo gremial que se propone para el estudio en el presente trabajo ha sido objeto de interesantes perspectivas particulares. Se ha sometido a examen como ejemplo su funcionamiento social, profesional y económico en ciudades como Zaragoza y Burgos a lo largo del siglo $\mathrm{XV}^{1}$, así como en el territorio valenciano durante la Edad Moderna ${ }^{2}$ y en la Málaga de los albores de la misma época ${ }^{3}$. Se ha proyectado este análisis en el Madrid del siglo XVII ${ }^{4}$ y se han proporcionado horquillas cronológicas más abiertas para otros puntos geográficos peninsulares, como Santiago de Compostela y Betanzos ${ }^{5}$. Sus parámetros de religiosidad colectiva también se nos han desvelado para ciudades como Sevilla y Jaca ${ }^{6}$. A lo que se añade la contemplación de variados detalles acerca de la legislación que los regía ${ }^{7}$, las relaciones de género producidas en el propio seno gremial$^{8}$, así como su constatada fortuna paremiológica ${ }^{9}$. En los últimos años se ha procedido a glosar su comportamiento gremial ante el Tribunal de la Santa Inquisición ${ }^{10}$.

1 M. I. Falcón Pérez, "Sobre la industria del vestido en Zaragoza en el siglo XV: las ordenanzas de la cofradía de sastres, calceteros y juboneros", Aragón en la Edad Media, 12 (1995), pp. 241-266; J. D. González Arce, "De la corporación al gremio. La cofradía de sastres, jubeteros y tundidores burgaleses en 1485", Studia historica. Historia medieval, 25 (2007), pp. 191-219.

2 R. Sanchís Llorens, "El offici de sastres y calcetters de Alcoy", en Primer Congreso de Historia del País Valenciano: celebrado en Valencia del 14 al 18 de abril de 1971, vol. 3, Valencia, 1976, pp. 201-208; R. de la Puerta, "Los avatares del asociacionismo de los artífices del vestir en la Valencia Moderna", en L. Prats (coord.), Estudios en homenaje a la Profesora Teresa Puente, vol. 2, Valencia, 1996, pp. 481-495. R. de la Puerta, Historia del gremio de sastres y modistas en Valencia: del siglo XIII al siglo XX, Valencia, Ayuntamiento, 1997.

3 V. Carretero Rubio, La artesanía textil y del cuero en Málaga (1487-1525), Málaga, Cedma, 1996.

4 J. C. Zofío Llorente, "Reproducción social y artesanos. Sastres, curtidores y artesanos de la madera madrileños en el siglo XVII", Hispania: Revista española de Historia, 71/237 (2011), pp. 87-120. J. C. Zofío Llorente, Gremios y artesanos en Madrid, 1550-1650: la sociedad de trabajo en una ciudad cortesana preindustrial, Madrid, CSIC, 2005; J. A. Nieto Sánchez, "La conflictividad laboral en Madrid durante el siglo XVII: el gremio de sastres", en Actas del I Congreso de jóvenes Geógrafos e Historiadores, 1995, pp. 283289; J. A. Nieto Sánchez, Artesanos y mercaderes: una historia social y económica de Madrid (1450-1850), Madrid, Fundamentos, 2006; T. Puñal Fernández, Los artesanos de Madrid en la Edad Media (1200-1474), Madrid, UNED, 2000.

5 F. Bouza Brey, "Historia de la cofradía gremial de sastres de Santiago de Compostela", Revista Compostellanum, 7 (1962), pp. 569-620; C. Vaamonde Lores, "La cofradía de los sastres de Betanzos", Boletín de la Real Academia Galega, 46 (1911), pp. 244-251.

6 J. F. Haldón Reina, "Aproximación histórico-artística a la antigua Hermandad de Nuestra Señora de los reyes del gremio de sastres", en J. Roda Peña (coord.), II Semana de estudios Medievales, Nájera, 2009, pp. 155-190; J. Gestoso Pérez y M. Fernández Gómez, Noticia histórico-descriptiva del antiguo pendón de la ciudad de Sevilla y de la bandera de la Hermandad de los sastres, Sevilla, Área de Cultura, 1999; M. Gómez de Valenzuela, "La regla de la cofradía jaquesa de sastres, bajo la advocación de San Lorenzo (1602)", Argensola: Revista de CC. Sociales del Instituto de Estudios Altoaragoneses, 113 (2003), pp. 315-328.

7 J. Baleztena Abarrategui, "Ordenanzas contra los sastres que tuvieren paños faltosos (1533)", Cuadernos de etnología y etnografía de navarra, 74 (1999), pp. 563-570; M. Á. Rodríguez Plaza, "Ordenanzas del gremio de sastres de Plasencia. Año 1795", Revista de estudios extremeños, vol. 71, n. 2 (2015), pp. 1115-1136.

8 R. Reguera Ramírez, "Costureras versus sastres. También una cuestión de género", El Pajar: Cuaderno de etnografía canaria, 25 (2008), pp. 110-116; A. Martínez Carreño, "Sastres y modistas: notas alrededor de la historia del traje en Colombia", Boletín Cultural y Bibliográfico, vol. 28, n. 28 (1991), pp. 61-76.

9 R. Monner Sans, De sastres: entretenimiento paremiológica, Talleres de la Casa Jacobo Peuser, 1909; J. Fernández García, "La consideración social de los sastres en la tradición asturiana: (poesía popular y paremiología)", en A. C. Polledo Arias (coord.), Fiestas Balesquida, Oviedo, 2012, pp. 89-103.

10 A. Marchant Rivera, "Los sastres en los Procesos de fe del tribunal de distrito de la Inquisición de Toledo (1483-1597)", Documenta \& Instrumenta, 12 (2014), pp. 95-116; J. M. Nombela Rico, Auge y decadencia en la 
El artículo se propone desentrañar, en primer lugar, las coordenadas socio-económicas de este colectivo gremial en el contexto de su relación con el estamento nobiliario. Pasar a continuación a abordar la relación de estos artesanos con los monarcas que detentaron la Corona de Castilla, y sus cortes, en la horquilla cronológica señalada, ejemplificando el proteccionismo regio hacia los mismos en la figura de Juan de la Hera, sastre y calcetero del príncipe don Juan. Para concluir con las interacciones de este oficio en la corte con otras dedicaciones profesionales vinculadas, como los mercaderes de tejidos, así como determinar la naturaleza y conformación estética de las creaciones que los sastres produjeron en el periodo.

Para ello, trabajaremos con la documentación albergada en el recientemente independizado Archivo Histórico de la Nobleza, en especial con los fondos de la sección de Osuna. E igualmente se hará uso de la documentación custodiada en el Archivo General de Simancas, cuyos fondos reflejan la estructura administrativa de la Monarquía Hispánica en la etapa seleccionada, atendiendo especialmente a las secciones Consejo Real de Castilla y Cámara de Castilla, Registro General del Sello y Consejo de Estado. Igualmente se atenderá a la serie documental del Registro de ejecutorias del Archivo de la Real Chancillería de Valladolid, por la visión panorámica que pueda ofrecernos de la organización judicial de esta etapa, en los casos concernientes a este colectivo gremial, así como por las trazas de historia económica y social que de ellos pueda derivarse.

\section{EL ARTE SARTORIAL Y SU RELACIÓN CON LA CORONA Y NOBLEZA CASTE-}

\section{LLANAS (1450-1615)}

3.1 La dignidad social del sastre: deseos de medrar y acumulación de ocupaciones. La relación sastre-nobleza o la reiterada insatisfacción de las deudas

El colectivo sartorial, sacudido en la época por los ávidos deseos de medrar como individuos a nivel profesional más que como corporación gremial en numerosas ocasiones, aprovecha las circunstancias económicas vinculadas a los solares geográficos donde ejercían su desempeño. De ahí que no resultara extraño que, para poder satisfacer las deudas a las que constantemente los sometía la clientela, de cualquier estamento social, algunos sastres contaran con la presencia de un criado en su entorno doméstico, a quienes solían entregar poderes para que, en su nombre, cobraran las cantidades pendientes. Tal es el caso del sastre Diego de la Calle, quien el 10 de septiembre de 1562 otorga una carta de poder a su criado Diego de Gordón, para que pudiera cobrar en su nombre todas las cantidades que le adeudaban ${ }^{11}$.

El asentamiento de la corte durante la segunda mitad del siglo XVI en la villa de Madrid $^{12}$ motivaría la presencia en la misma de numerosos sastres denominados en las fuentes documentales como "andantes" o "estantes" en corte. Tenemos constancia de que uno de estos sastres estantes en corte fue Silvestre Laso, a quien conocemos por un pleito que transcurre entre los años 1556 y 1560, en el que el platero vallisoletano Francisco Angulo arremete contra él por un préstamo de dinero ${ }^{13}$. Igualmente por otro pleito del año 1560 ,

España de los Austrias: la manufactura textil de Toledo en el siglo XVI, Toledo, Ayuntamiento, 2003.

11 Archivo Histórico de la Nobleza (AHN), Osuna, C. 870, D.127.

12 A. Domínguez Ortiz, "Madrid de villa a corte", en Historia y documentos notariales, Madrid, 1992, 16-2, pp. 263-279; M. I. Mediero Velasco, "El impacto de la corte sobre la villa de Madrid", Pasea por Madrid: historia, turismo cultural y tiempo libre, 7 (2015), pp. 39-57; A. Alvar Ezquerra, El nacimiento de una capital europea: Madrid entre 1561 y 1609, Madrid, Turner, 1989; J. M. López García, El impacto de la corte en Castilla: Madrid y su territorio en la época moderna, Madrid, siglo XXI de España, 1998.

13 Archivo General de Simancas (AGS), Consejo Real de Castilla (CRC), 334, 9. 
en esta ocasión contra el calcetero toledano Pedro de Salas, conocemos a Maese Gaspar, sastre andante en corte por las mismas fechas, quien le reclama al calcetero el pago del alquiler de una casa ${ }^{14}$. En el año 1562 es otro sastre estante en corte, Diego de Aranda, quien emprende un pleito contra íñigo López de Ávalos, que había ejercido como camarero del Marqués de Villena, por una deuda de hechura de ropas ${ }^{15}$. Y entre los años 1557 y 1563 transcurre un pleito contra Luis de Villalón y Hernán Núñez de Artiaga, fiadores de una obligación hecha por el sastre Juan Vicente Campel, documento que nos da a conocer a este otro artesano andante en corte, quien reclama la devolución de sus 200 ducados $^{16}$.

La constante de la insatisfacción de las deudas, a la que ya nos hemos venido refiriendo, se acentúa cuando los ejecutores del arte sartorial entregan sus trabajos y prendas a miembros del estamento nobiliario, algunos de los cuales se destacan notablemente por su constante elusión de pagos, como enseguida veremos.

A 29 de julio de 1489 está fechada una carta para que Pedro González Venegas, señor de la Villa de Luque, pague al sastre Ruy Fernández, vecino de Córdoba, 2.500 maravedís que le debe en concepto de pago de hechuras de prendas de vestir ${ }^{17}$. De este sastre Ruy Fernández nos consta que al menos tuvo un hijo llamado Gonzalo, que había sido agredido por una pedrada de Martín, hijo de Diego Sánchez de Aguilar, también vecino de Córdoba, quien aparece protagonizando un perdón de Viernes Santo fechado a 25 de abril de 1480 desde la ciudad de Toledo ${ }^{18}$. En el año 1562 el sastre Diego López, vecino de Madrid, mantiene un litigio con Antonio de Guzmán, alcaide de El Pardo, por el pago de las ropas que le hizo, que se tardaba en consumar ${ }^{19}$.

Algunas mujeres de la nobleza, como es el caso de doña María de Silva de Guevara, madre de Don Álvaro de Ayala, alguacil mayor de Toledo y mujer de Don Fadrique Manrique de $Z$ Zúñiga ${ }^{20}$, aprovechaban la figura del sastre regio para adquirir tejidos, que luego empleaban en confeccionar vestidos sin la intervención del sastre real, es decir, acudiendo a sastres ordinarios o modistas del entorno geográfico, o incluso, demandando los favores profesionales de los sastres andantes en corte; tejidos que luego se olvidaban de pagar al sastre real, por descuido o por ver si la cercanía regia diluía su propia responsabilidad. Así, el 15 de febrero de 1498 se ordena que la propia doña María de Silva de Guevara pague al sastre real Fernando de Torrijos lo que le debe por las telas que le compró ${ }^{1}$.

Entre los años 1568 y 1615 registramos variados documentos que hilvanan un tira y afloja constante en la relación de la casa del V Conde de Alba de Liste con los protagonistas del gremio de sastres. Así el 16 de octubre de 1568 se produce un contrato celebrado entre el sastre Sebastián Gutiérrez y Diego Enríquez de Guzmán, V conde de Alba de Liste, contrato que glosa un encargo de prendas del que no tenemos constancia si se efectuó el pago $^{22}$. Cuatro años más tarde, concretamente el 10 de abril de 1572, localizamos una carta de poder otorgada por el sastre Antón de Aguiare, vecino de Zamora, a su sobrino, para

14 AGS, CRC, 515, 16.

15 AGS, CRC, 744, 38.

16 AGS, CRC, 335, 8.

17 AGS, Registro General del Sello (RGS), LEG., 148907, 85.

18 AGS, RGS, LEG., 148004, 43.

19 AGS, CRC, 666, 8.

20 L. Salazar y Castro, Pruebas de la historia de la casa de Lara sacadas de los instrumentos por..., Madrid, Imprenta Real, 1694, p. 102.

21 AGS, RGS, LEG, 149802, 100.

22 AHN, Osuna, C. 873, D. 34. 
cobrar una libranza a Juan Cuello, vecino de Bembibre (León) y mayordomo de Diego Enríquez de Guzmán, V Conde de Alba de Liste ${ }^{23}$. Tres años más tarde, el 1 de febrero de 1575, se documenta otro caso análogo que en esta ocasión implica a la condesa doña María de Urrea. Se trata del traslado de la carta de poder otorgada por el sastre Hernán Gutiérrez a favor de Juan de Llanos, para cobrar en su nombre de Juan González Rodríguez, mayordomo en Villavicencio - de los Caballeros (Valladolid) - de la condesa de Alba de Liste, María de Urrea, cierta cantidad que le debían ${ }^{24}$. Esta persecución por morosidad halla una tregua en los años iniciales del siglo XVII, cuando documentamos unas cartas de pago otorgadas por Antonio de Llanos, tesorero del Conde de Alba de Liste, y por el sastre madrileño Diego de Alfaro, de unos trajes que realizó para el conde. Las cartas están datadas en Valladolid, a 29 de julio de 1604 y en Zamora, a 21 de enero de 1615, respectivamente ${ }^{25}$. Y recogen ante la fe pública del escribano de provincia Martín Romero un pago aplazado de 500 reales anuales fiados por el mercader Diego de Quirós:

En la villa de Madrid a primero día del mes de junio de mil e seiscientos y doze años ante mí el presente escribano y testigos deyuso escritos pareció presente Don Diego de Alfaro, sastre vezino desta villa, y dijo que él tiene puesta demanda de mil y tantos reales a su Excelencia el Conde de Alba ante Martín Romero, escribano de provincia, de ciertas obras y hechura de vestidos que a hecho para su excelencia y su casa [...] y lo tasaron en cierta cantidad y agora el dicho Diego de Alfaro por bien de paz rescibe de su Excelencia del dicho Señor Conde quinientos reales por año de Diego de Quirós, mercader, de que yo el presente escribano doy $\mathrm{fe}^{26}$.

\subsection{Los sastres y su relación con la Corona castellana (1450-1615). Francisco de la Hera, sastre y calcetero del príncipe don Juan}

Un requerimiento fechado a 18 de febrero de 1484, para que Juan Herrador, vecino de Fontiveros, restituya un huerto que en este lugar tenía tomado, nos permite conocer al sastre de Sus Altezas Fernando de la Fuente, personaje que en este caso es quien resulta agraviado ${ }^{27}$. Seis años más tarde se localiza una carta, con fecha de 21 de julio de 1490, en la que se concede el beneficio de San Juan de la villa de Arjona a Diego García de Torrijos, hijo de Juan de Torrijos, denominado este último en las fuentes como sastre de los Reyes ${ }^{28}$. Una ejecutoria otorgada en Sevilla a 26 de febrero del año 1500 por los propios Reyes Católicos contra este mismo personaje, el sastre regio Juan de Torrijos, nos da a conocer el pleito que trató con Mencía Rodríguez de San Pedro, viuda de Gonzalo Rodríguez de San Pedro, vecino de Torrijos, condenado por hereje, sobre los bienes dotales y patrimoniales de la dicha Mencía, que le terminan siendo restituidos ${ }^{29}$.

Poco más de diez años más tarde, el 15 de enero de 1501, desde la ciudad de Granada se le ordena a Sancho de Paredes, camarero de la Reina, que entregue de los 750.000 maravedís recibidos de Gabriel Sánchez, tesorero del Rey, como pago a Fernando de Torrijos, sastre, 8.000 maravedís por vestidos que había confeccionado para la Reina de

23 AHN, Osuna, C. 873, D. 43-44.

24 AHN, Osuna, C. 870, D. 148.

25 AHN, Osuna, C. 870, D. 182-184.

26 Comisión Internacional de Diplomática, Folia Caesaraugustana I (normas de transcripción y edición de documentos), Zaragoza, CSIC, Institución Fernando el Católico, 1984.

27 AGS, RGS, LEG, 148402, 152.

28 AGS, RGS, LEG, 149007, 141.

29 AGS, RGS, LEG, 150002, 105. 
Portugal y para la Infanta Catalina. Con lo que entendemos que este Fernando de Torrijos pudiera haber sido hermano o hijo del anterior, materializando así la adhesión a la corona de una misma saga familiar sartorial:

La Reyna. Sancho de Paredes mi camarero yo vos mando que de las seteçientas e çinquenta mil maravedís que vos por mi mandado resçibistes de Graviel Sanches tesorero del Rey mi señor deys luego a Fernando de Torrijos sastre ocho mil maravedís los quales le dad para en cuenta a pago de los vestidos que él a fecho para la Reyna de Portugal e para la Ynfanta doña Catalina mis muy caras e amadas fijas e dadgelos e tomad su carta de pago del dicho Fernando de Torrijos con la qual e con esta cuando a los mis contadores mayores de cuentas que vos rexçiban e pasen en cuenta los dichos ocho mil maravedís $[\ldots]^{30}$

Ya que interviene de nuevo activamente en la corte como sastre de la Princesa de Gales, a quien efectúa las hechuras de unas ropas; hechuras por las que se le ordena pagar a Alonso de Morales el 12 de octubre de 1501 en la ciudad de Granada, al dicho sastre Fernando de Torrijos, la cantidad de 19.000 maravedís ${ }^{31}$.

El 14 de diciembre de 1500 en la ciudad de Granada la Reina Isabel ordena a su camarero, Sancho de Paredes, que entregue a su criada Beatriz Galindo una mantilla de sarga recibida de Mena Ote, que por aquel año actuaba como sastre del Rey ${ }^{32}$. Y un año más tarde, en concreto el 22 de mayo de 1501, también desde la misma ciudad, la orden explícita a Alonso de Morales, tesorero de la Reina, para que libre al sastre de la princesa de Gales 3.000 maravedís de ayuda de costa, nos da a conocer la figura de otro sastre regio, Diego de Pedrosa ${ }^{33}$. Así pues, observamos que en el mismo año de 1501 cosen para la princesa de Gales dos sastres en la corte castellana, Fernando de Torrijos y Diego de Pedrosa, nada extraño si recordamos que se trata del año en el que contrae matrimonio la Infanta Catalina con Arturo, Príncipe de Gales, por lo que se hacía necesario ampliar su indumentaria como vestimenta para el ajuar ${ }^{34}$.

El 9 de abril de 1503 se deja constancia documental desde la ciudad de Alcalá de Henares de quién actuó como sastre de infantes regios, pues se ordena a Martín de Salinas, tesorero de los descargos de la Reina, que pague lo que se deba a Alonso Gallego, "sastre que fue del difunto príncipe don Miguel, mi nieto ${ }^{35 "}$ :

Martín de Salinas tesorero de mis descargos yo vos mando que de qualesquier maravedís de vuestro cargo dedes e paguedes a Alonso Gallego sastre que fue del Príncipe don Miguel mi nieto que está en la Gloria seys mill e quinientos e sesenta maravedís que es mi merçed de le mandar librar para complimiento de todo lo que le es deuido por las fechuras e por otro qualquier cargo en que le sea de qualesquier ropas e hornamentos quél hizo por mi mandado los años pasados de DI e DII e no le han seydo pagadas [...] e tomad su carta de pago con las (tachado) o de quien su poder oviere...

30 AGS, CCA, CED, 5, 3, 3.

31 AGS, CCA, CED, 5, 286, 4.

32 AGS, CCA, CED, 4, 259, 5.

33 AGS, CCA, CED, 5, 129, 3.

34 J. M. Bello León y M. B. Hernández Pérez, "Una embajada inglesa a la corte de los Reyes Católicos y su descripción en el 'Diario' de Roger Machado”, En la España medieval, 26 (2003), pp. 167-202.

35 AGS, CCA, CED, 6, 81, 3. 
Figura 1. Que se pague lo que se debe a Alonso Gallego, sastre del difunto príncipe Don Miguel

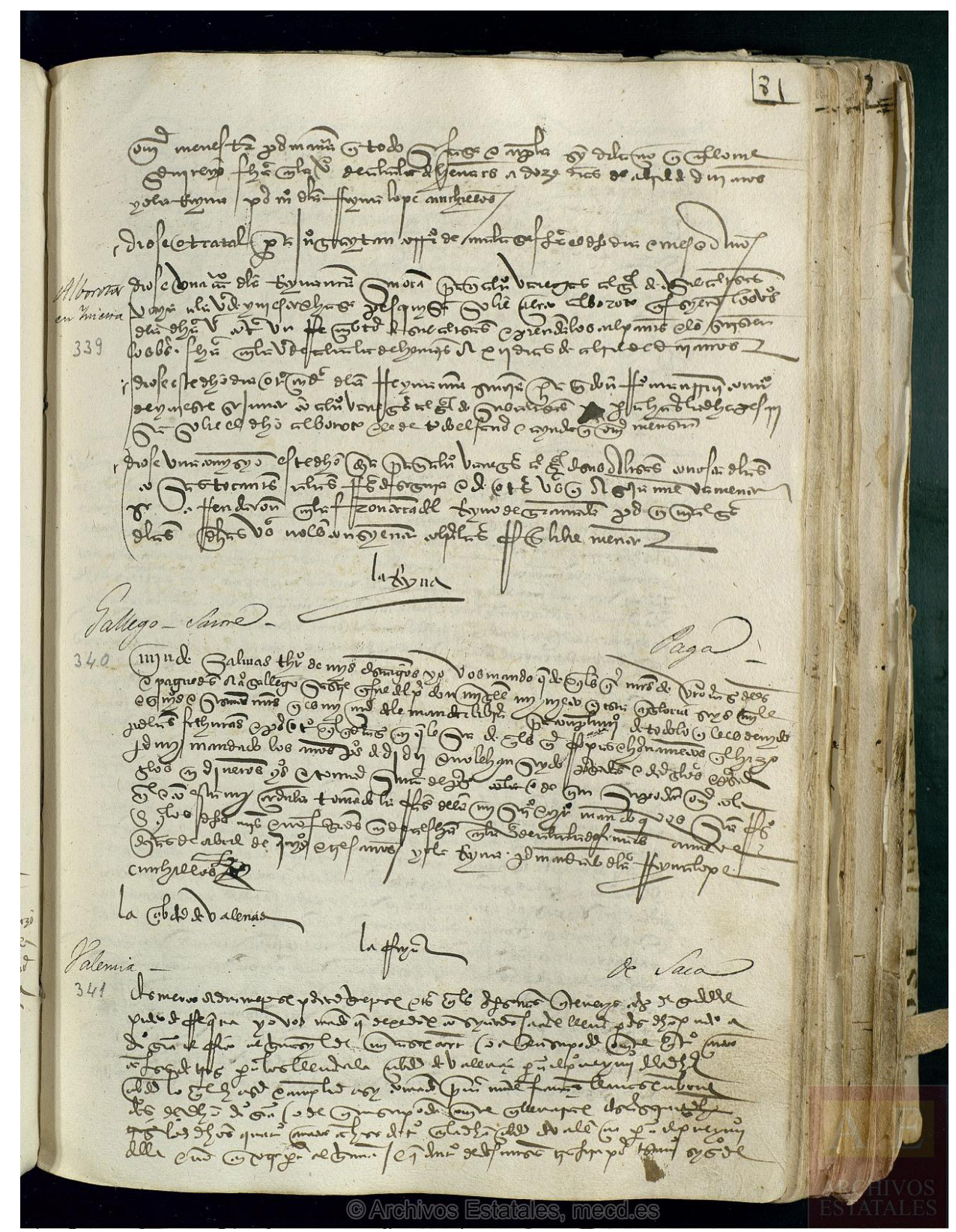

Ya para el siglo XVI conocemos la figura de Adrián, a quien las fuentes denominan sastre de los arqueros de la guardia del Rey, el Emperador Carlos I, como factor de prendas específicas para cuerpos militares del entorno más cercano al monarca, quien litiga un pleito del que tenemos constancia por ejecutoria fechada a 19 de marzo de $1535^{36}$.

El día 20 de febrero de 1587 da fecha a otra ejecutoria del pleito litigado por el madrileño Bartolomé Domínguez, como curador de Luisa de Herrera, contra Luisa de Treviño, vecina también de Madrid y viuda de Francisco de Herrera, sastre del príncipe, padre de la parte contraria, sobre la entrega de parte del dinero obtenido en la venta de unas casas situadas en la calle del Mediodía, junto a la Puerta de Toledo, que había dejado al morir el

36 Archivo de la Real Chancillería de Valladolid (ARCHV), Real Audiencia y Chancillería de Valladolid, Registro de ejecutorias, caja 464,60. 
dicho sastre del príncipe, Francisco de Herrera ${ }^{37}$. De lo que inferimos que el dicho Francisco de Herrera habría actuado como sastre real para el futuro monarca Felipe III.

Figura 2. Ejecutoria del litigio de Adrián, sastre de los arqueros de la guardia del rey

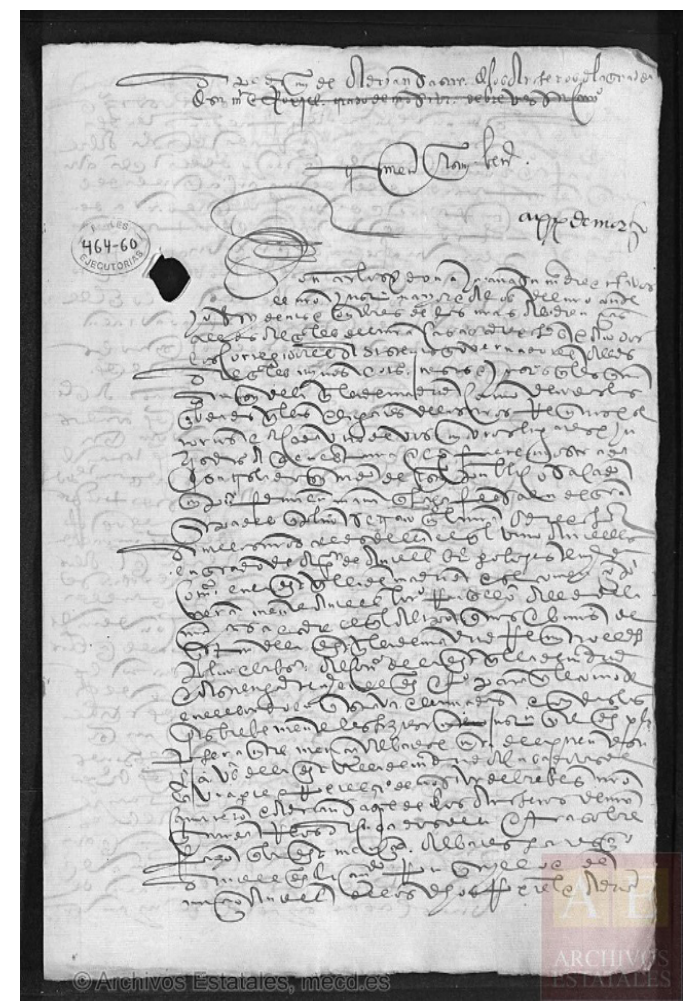

En el personaje de Francisco de la Hera concurre la doble condición de los oficios de sastre y calcetero para atender las necesidades de vestido del príncipe don Juan. Se ha podido reconstruir la identidad de algunos miembros de su familia, como sus nietas y su esposa, a través de sendos procesos documentales judiciales que vamos a pasar a presentar. En febrero del año 1493 se desarrolla un proceso relacionado con la familia de Francisco de la Hera, sastre y calcetero del príncipe don Juan. Desde la ciudad de Barcelona, el día 13 del citado mes y año, los Reyes Católicos se dirigen a las justicias, para que se informen acerca de Alonso de Escalona, vecino de Casarrubios, y si procede, le prendan por haber dado muerte a su mujer, Catalina de la Hera, hija de Francisco de la Hera, sastre y calcetero del Príncipe don Juan; se solicita que se entreguen las hijas de ambos al padre de ella, es decir al dicho sastre y calcetero real, junto a los bienes del dicho Escalona como ayuda de crianza $^{38}$.

Al día siguiente, desde la misma ciudad, los monarcas se dirigen a las justicias para que paguen a Francisco de la Hera, sastre y calcetero del Príncipe don Juan, con los bienes de su yerno, Alfonso de Escalona, vecino de Casarrubios, y para que se entreguen a las hijas de este; mientras el mencionado Alfonso de Escalona andaba prófugo después de haber acuchillado a su mujer, la hija del sastre ${ }^{39}$. 
La petición de ejecución de una sentencia dada en la misma ciudad de Barcelona el 7 de julio del mismo año nos revela que se había solicitado la pena de muerte contra Alfonso de Lerma "que se dice de Escalona", por haber matado en Casarrubios del Monte a su mujer, Catalina de la Hera, hija de Francisco de la Hera, sastre del Príncipe don Juan ${ }^{40}$. Siete años más tarde, el 28 de marzo de 1500, un nuevo registro documental datado en la ciudad de Sevilla nos habla en favor de que se haga justicia a Elvira Flórez, mujer de Francisco de la Hera, sastre del príncipe don Juan, en el pago de las deudas de su hermano, Pedro Flórez, por parte de su cuñada y segundo marido ${ }^{41}$. No es de extrañar pues el proteccionismo hacia esta figura cercana al entorno regio ya que los datos aportados por la documentación conservada desvelan que muchos gastos, especialmente las vestimentas, fueron sufragados por la propia soberana; y que, en 1495, cuando el príncipe don Juan se emancipa, tiene que hacer frente en este sentido a varias deudas que su madre no llegó a pagar ${ }^{42}$.

Figura 3. Proceso de Francisco de la Hera, sastre del Príncipe Don Juan

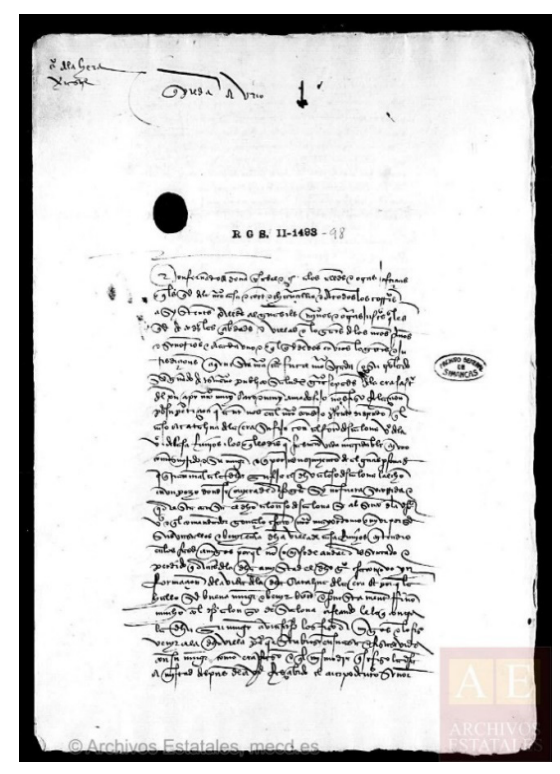

\subsection{Sastres y mercaderes en la corte castellana. Naturaleza de las creaciones de los sastres reales y estantes en corte}

Noticias de registros económicos como las contenidas en la sección Cámara de CastiIla del Archivo General de Simancas nos permiten entrever de qué naturaleza, calidad y procedencia eran los tejidos y géneros con los que los sastres reales elaboraban las prendas encargadas. En este contexto, la figura del mercader, en varias ocasiones registrado a nivel documental como mercader regio o de la reina, cobra también un especial protagonismo.

Así, el 30 de abril de 1494, desde Medina del Campo $^{43}$, se procede a dar orden a Juan Daza, mercader de la reina, para que entregue al granadino Juan de Baeza ocho varas de brocado pelo carmesí, otras ocho de brocado raso verde, diez varas de aceituní carmesí, otras diez de aceituní verde y otras diez de aceituní azul con destino al rey Muley Babdili y otros moros. A este mismo mercader se le da nuevamente orden desde Madrid, el 13 de

40 AGS, RGS, LEG, 149307,153.

41 AGS, RGS, LEG, 150003,428.

42 J. D. González Arce, La casa y corte del príncipe don Juan (1478-1497): economía y etiqueta en el palacio del hijo de los Reyes Católicos, Sevilla, Sociedad Española de Estudios Medievales, 2016.

43 AGS, CCA, CED, 1, 41, 1. 
enero de 1495, para que de los maravedís de que tuvo cargo para pagar a "las niñas de mi casa" (las hijas de las criadas de la Reina) entregue cierta cantidad a Isabel de Ribera, hija de María de Medina, criada de la Reina ${ }^{44}$. En otras ocasiones es el propio mercader el que recibe el pago que queda registrado en la cámara regia, como en la nota del día 20 de julio de 1501, en la que desde Granada se da orden al tesorero Gonzalo de Baeza para que le pague al mercader Juan Daza cierta cantidad en concepto de las tapicerías de figuras que compró por mandato de la Reina ${ }^{45}$.

En las postrimerías del siglo XV e inicios del XVI en la corte granadina no solo hallamos la figura del mercader Juan Daza, sino que junto a él opera con solvencia otro mercader denominado Juan de Alzaga ${ }^{46}$. El 15 de diciembre del año 1500 Gonzalo de Baeza, tesorero de la reina, recibe orden de pagar al mercader Juan de Alzaga doce varas de terciopelo carmesí que dio para confeccionar un vestido de la Infanta Catalina ${ }^{47}$. El mismo Gonzalo de Baeza, actuando como tesorero de la princesa doña Juana, recibe nuevamente orden de satisfacer cierta cantidad al mercader Juan Alzaga, estante en la corte, por las telas que entregó a Sancho de Paredes "mi camarero, que se relacionan":

Por quatorze varas de seda terçiopelo negro doble que del se conpraron para dar a Madona de Aluy (?) Dueña de la Ylustrísyma my muy cara e amada fija a dos ducados cada vara que son diez mil quinientos maravedís. Mas por çinco varas e dos terçios de paño negro de Valençia para dar a la dicha Madona de Aluy (?) a razón de a dos ducados la vara que son XIIII (tachado) quatro mil e dosyentos e çinquenta maravedís [...] mas por çinco varas e quarta de terçiopelo negro doble que del se compraron para una silla de mí la Reyna a dos ducados que son III (tachado) III.DCCCXXXVII maravedís ${ }^{48}$.

El 15 de enero del año 1501, Gonzalo de Baeza, tesorero de la reina, libraría a otros dos mercaderes estantes en la corte, Martín Centurión y a Diego de la Fuente, la cantidad de maravedís correspondientes a 24 varas de terciopelo leonado que habían entregado en concepto de dos vestidos que se elaboraron para la Reina ${ }^{49}$.

El 5 de enero de 1501, víspera de la Epifanía, en la ciudad de Granada, los escribanos de cámara de la reina reciben orden para entregar al camarero Sancho de Paredes la cantidad del pago de sesenta y dos armiños empleados para elaborar un vestido de terciopelo verde de la Infanta doña Catalina, junto con veinte varas de cintas verdes ${ }^{50}$.

Por esas mismas fechas, se presume que la infanta Doña Catalina, princesa de Gales, disfrutó de un vestido de dos brocados, uno de pelo morado y otro de raso blanco. La entrega de los tejidos la efectuó el camarero real Sancho de Paredes, con conocimiento de Francisca de Torres, camarera de la Infanta, el 10 de febrero de $1501^{51}$. Pero no solo los tejidos en la corte sirvieron para cubrir vistosamente los cuerpos regios, como podrá aventurarse. Si antes notificábamos la compra de unos tejidos para tapicería, en otras ocasiones los mismos eran usados para guarnecer libros, probablemente empleados personalmente

44 AGS, CCA, CED, 2, 2-1, 5, 1.

45 AGS, CCA, CED, 5, 192, 7.

46 Una ejecutoria registra el pleito litigado por Juan del Uva, vecino de Salinas de Leniz (Gipúzcoa), sobre restitución de dos manzanales. ARCHV, Registro de Ejecutorias, Caja 301, 36. 5-5-1515.

47 AGS, CCA, CED,4, 245,1.

48 AGS, CCA, CED, 6, 180, 3.

49 AGS, CCA, CED, $5,6,4$

50 AGS, CCA, CED, 4, 271, 2.

51 AGS, CCA, CED, 5,55,5. 
por la reina. Tal es que el 20 de julio de 1501 desde Granada, se da orden a Sancho de Paredes para que entregue a Diego Cano, contino, unas piezas de terciopelo y raso negro por las que empleó para guarnecer un libro ${ }^{52}$.

Figura 4. Libranza a Martín Centurión y Diego de la Fuente, mercaderes estantes en corte

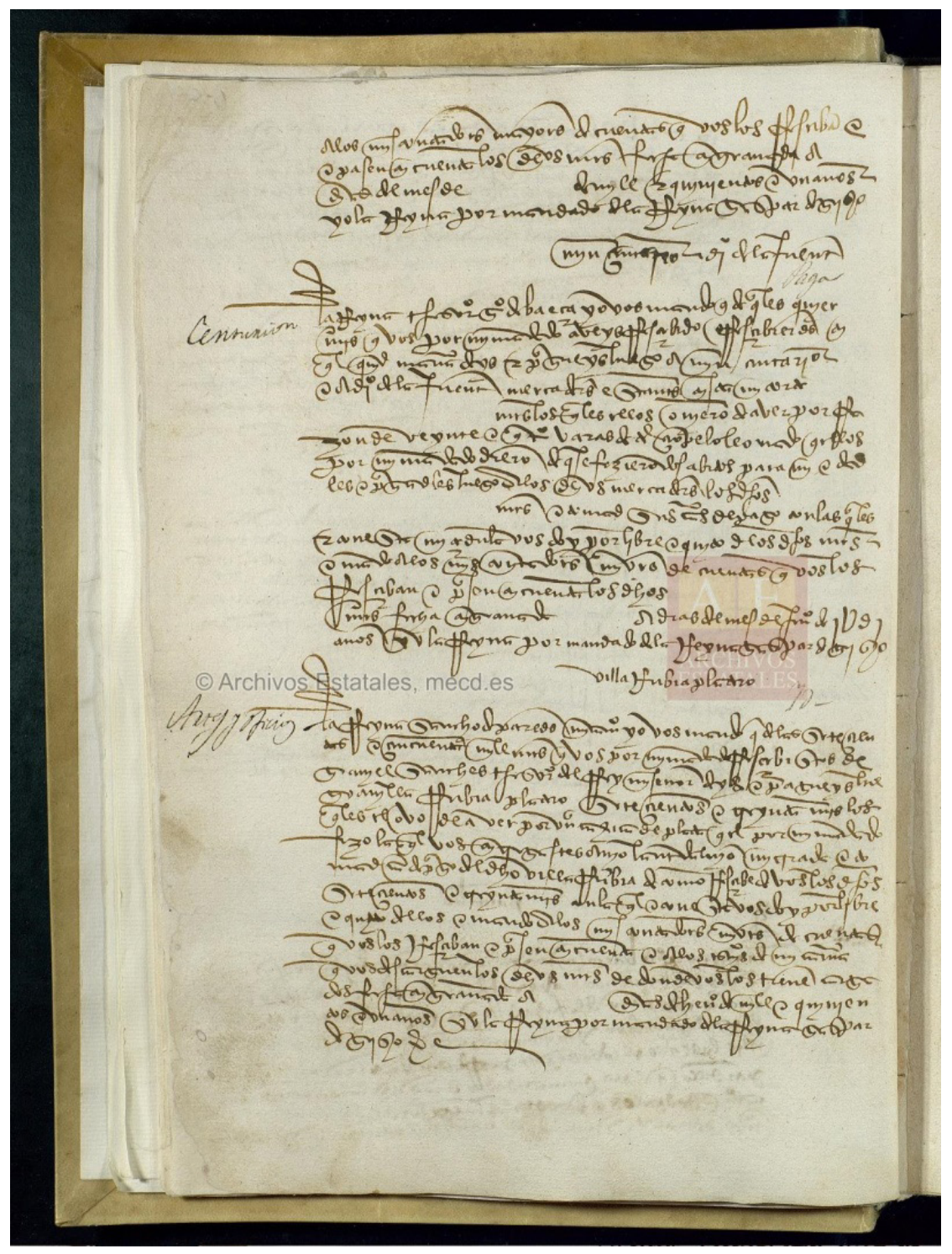


Figura 5. Libranza a Sancho de paredes para un vestido de terciopelo verde de la Infanta Doña Catalina

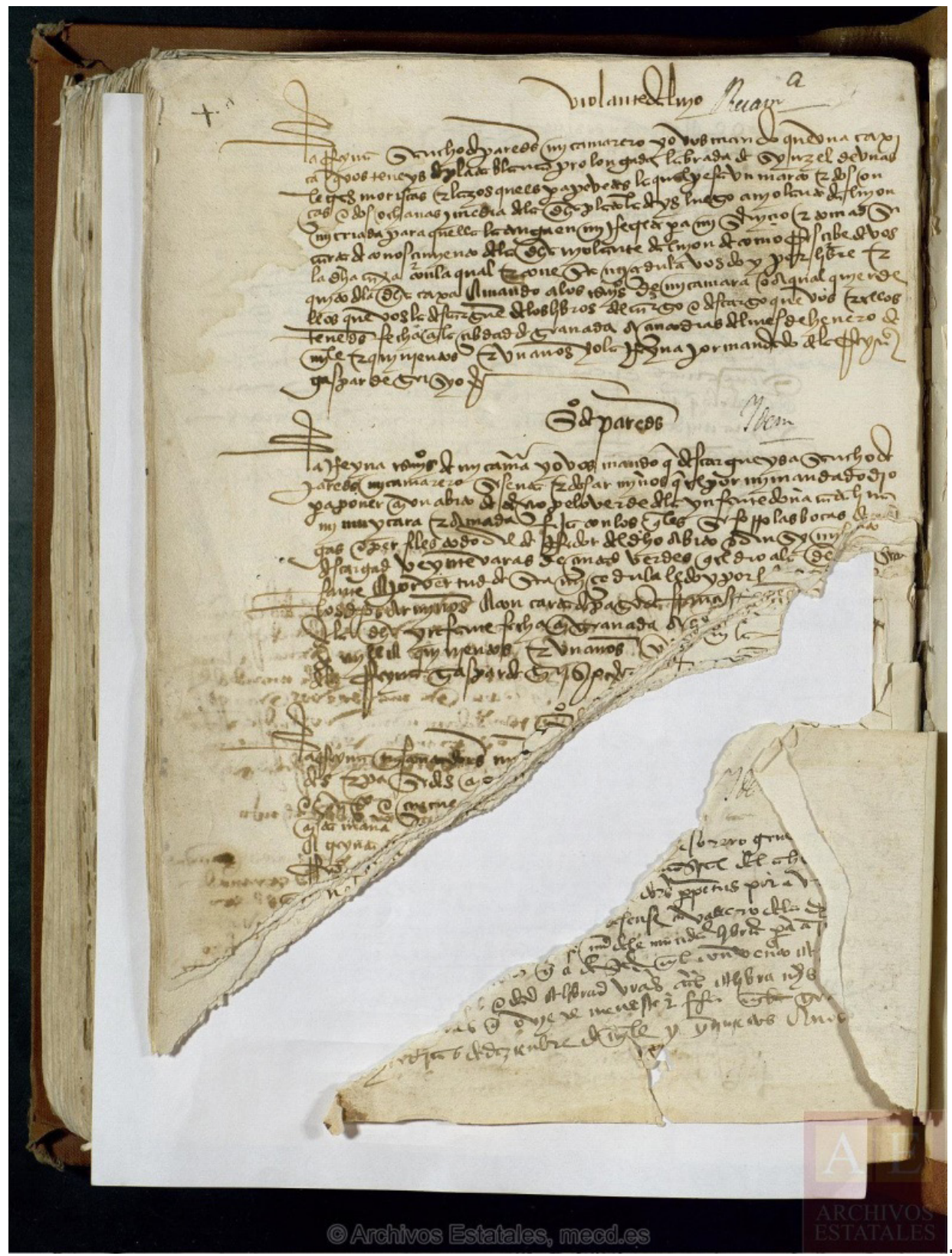

Por las referencias de la misma sección archivística mencionada, la de Cámara de Castilla, y en el entorno del desempeño del arte sartorial en la corte, también podemos conocer los tejidos e indumentaria que gastaban las mujeres más cercanas al entorno de Isabel la Católica, es decir, sus amigas, mujeres de confianza y criadas. El 8 de enero de 1501 desde Granada, se ordena al camarero de la reina, Sancho de Paredes, que entregue a su homólogo del Rey, Mosén Juan Cabrero, cinco varas y una cuarta de terciopelo leonado, procedentes de las cinco varas y media recibidas de Beatriz Cuello, camarera de la reina, ya difunta, e hija del camarero Sancho de Paredes ${ }^{53}$. La misma Beatriz Cuello había recibido el 5 de agosto de 1500, de manos de su padre, un mongil de paño fino negro y una toalla de manteles listada de azul por orden de la reina ${ }^{54}$. 
El 30 de octubre del año 1500, Beatriz Galindo la Latina, documentada en las fuentes como criada de la reina, recibe de manos del camarero de la reina, Sancho de Paredes, "un hábito de terçiopelo verde oscuro, de mangas cortas y una mantilla de çebrín leonado con dos aletas ${ }^{55 " .}$

Figura 6. Para que Sancho de paredes entregue vestidos a Beatriz Galindo La Latina

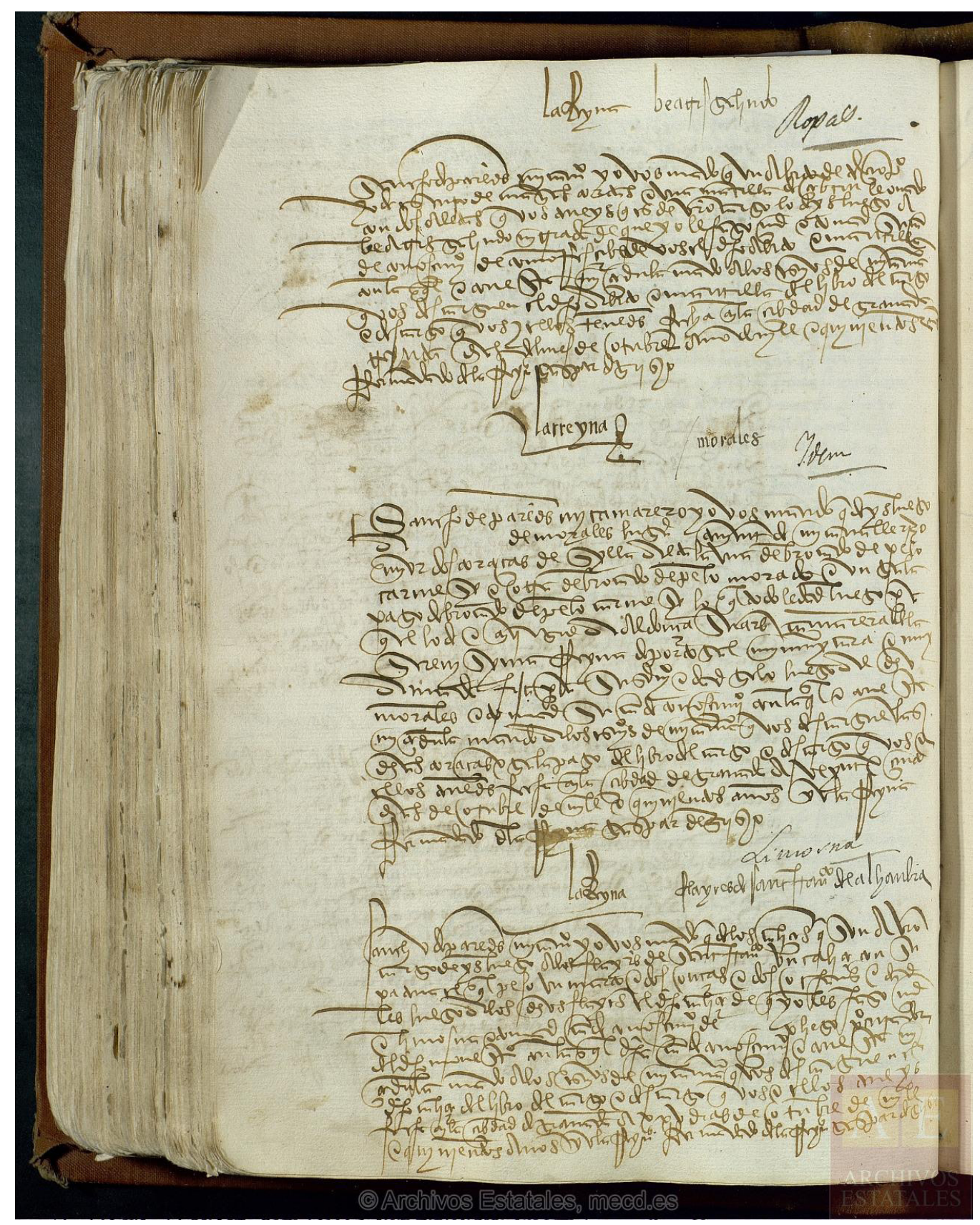

Por su parte, María de Medina, criada de la reina, recibe de manos de Gonzalo de Baeza diez varas de terciopelo morado como merced, orden datada a 9 de junio de 1501 en la ciudad de Granada ${ }^{56}$. Como puede apreciarse, en esa moda española que tan poderosamente llamó la atención de los foráneos se reconocía un estilo peculiar y diferente, basado

55 AGS, CCA, CED, 4, 211, 3.

56 AGS, CCA, CED, 5, 147, 5. 
en el uso habitual de las sedas, la combinación de telas y colores, la preferencia por los carmesíes y el empleo reiterado del oro en la confección de las prendas ${ }^{57}$.

La relación de gastos que registra la documentación de cámara también nos permite conocer el tipo de prendas que elaboraban los sastres regios o andantes en corte para los empleados de la misma. Así, Alfonso Nieto, mozo de espuelas de la reina, recibe de Gonzalo de Baeza el 19 de septiembre de 1500 las cantidades especificadas de tejido correspondientes a su librea: dos varas y media de terciopelo negro para su jubón y un bonete, tres varas y cuarta de grana colorada para un sayo y unas calzas, cinco varas de contray para un capuz y dos varas de Londres morado para un capotín ${ }^{58}$.

Figura 7. Libranza para la librea de Alfonso Nieto, mozo de espuelas de la Reina.

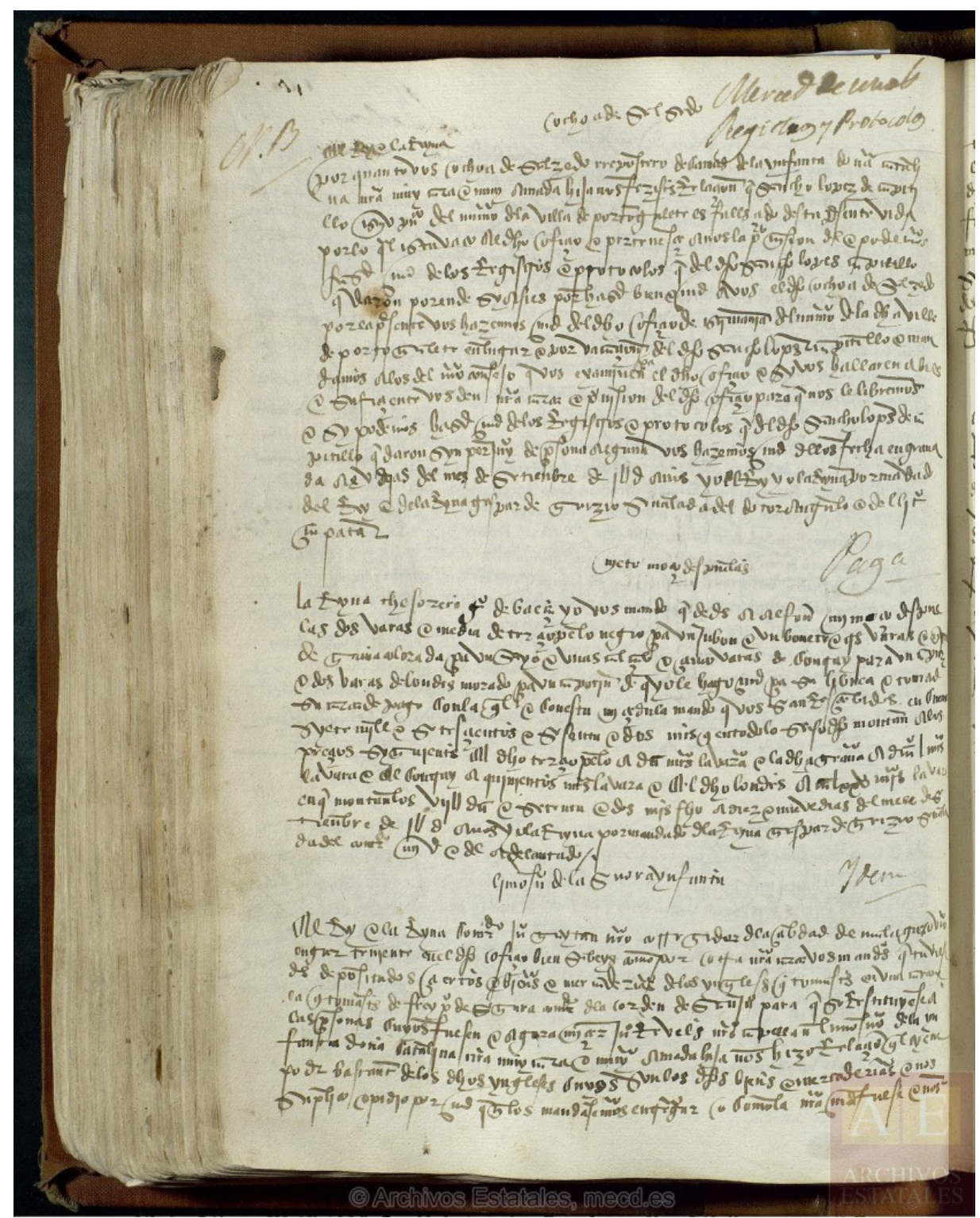

57 M. del C. González Marrero, "Un vestido para cada ocasión: la indumentaria de la realeza bajomedieval como instrumento para la afirmación, la imitación y el boato. El ejemplo de Isabel I de Castilla", Cuadernos del CEMyR, 22 (2015), pp. 155-194; J. M. de Francisco Olmos, "La evolución de los cambios monetarios en el reinado de Isabel la Católica según las cuentas del tesorero Gonzalo de Baeza", En la España medieval, 21 (1998), pp. 115-142.

58 AGS, CCA, CED, 4, 169, 4. 
E igualmente en Granada, con fecha 6 de noviembre de 1500 se procede a dar orden a Sancho de Paredes para que entregue dos varas de terciopelo negro para un jubón y una caperuza para el hijo de Jerónimo de Palacios, carpintero de la reina ${ }^{59}$.

Del mismo modo, durante el reinado de Carlos I, la entrega de tejidos va a jugar un papel interesante en las misiones diplomáticas internacionales, ofrecidos como presentes muy apreciados. Así, en una carta del Embajador en Génova, Gómez Suárez de Figueroa, al Emperador Carlos V, fechada en esa ciudad a 7 de agosto de 1533, entre el apunte de los recelos que produce la proyectada entrevista del papa con el rey de Francia, la atracción de César Fragoso al servicio de Francia y gestiones con Bernabé Adorno, el registro de armas y armeros que envía de Alemania a España Enrique Welzer y los avisos de Suiza, se introduce noticia sobre las telas de terciopelo leonado que se habían encargado ${ }^{60}$.

Igualmente, en otra carta del mismo embajador Gómez Suárez de Figueroa a Juan Vázquez de Molina, secretario de Estado, fechada en la misma ciudad italiana a día 14 de julio de 1541, se departe sobre unos regalos de terciopelo de dos pelos, tafetán y conservas, con los que le obsequia ${ }^{61}$.

Figura 8. Regalos de tejidos a Juan Vázquez de Molina, secretario de Estado.

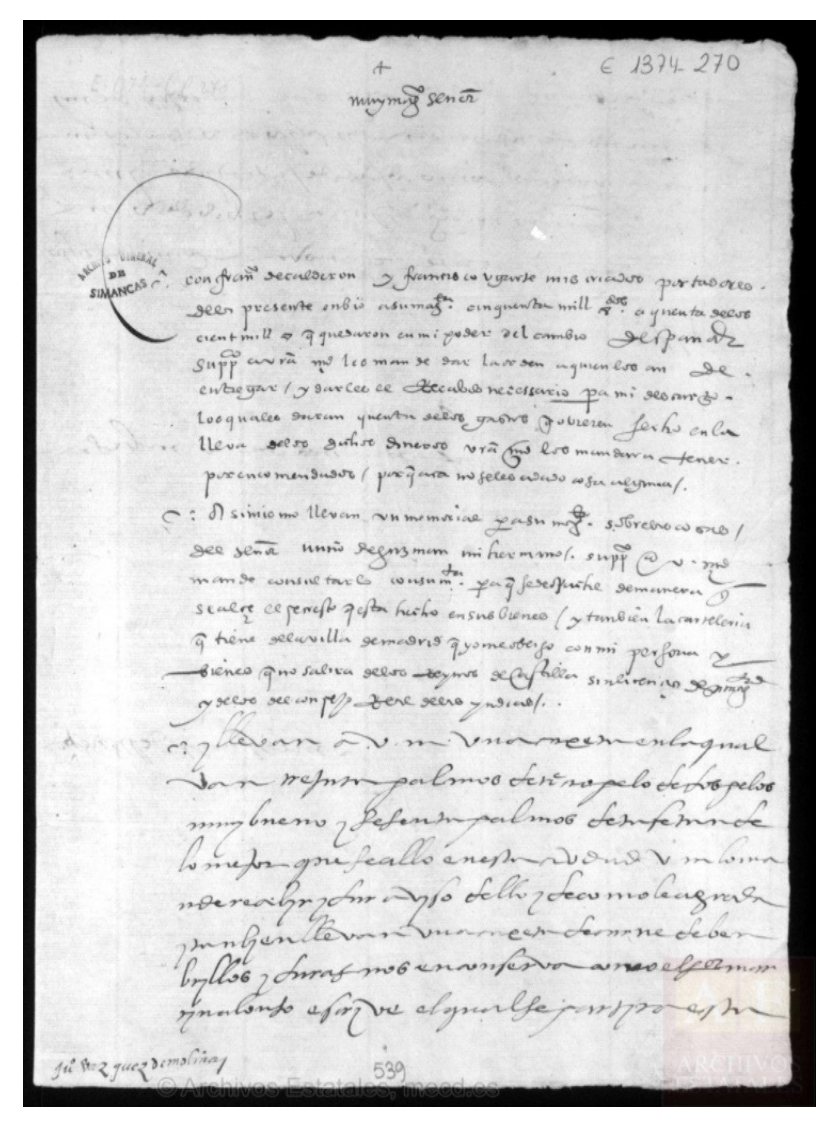

\section{CONCLUSIONES}

Con el presente trabajo se ha pretendido, sobre el colchón doctrinal y bibliográfico que registra la trayectoria de este gremio, aportar una nueva dimensión que nos pueden ofrecer

59 AGS, CCA, CED, 4, 220,1.

60 AGS, Consejo de Estado (EST), LEG, 1366, 230.

61 AGS, EST, LEG,1374, 270. 
las fuentes archivísticas y documentales para la época, esto es, la identificación, relación y análisis de la función ejercida por los sastres regios y vinculados por su profesión al estamento nobiliario. Desde los individuos portadores de una dignidad social in crescendo, con deseos de medrar en la escala social, como los sastres andantes y estantes en corte, hasta un grupo más consolidado marcado por la continua insatisfacción de las deudas en su relación con la nobleza. Secciones archivísticas como el Registro General del Sello, Cámara de Castilla, Registro de Ejecutorias o Estado han servido para proporcionarnos una nutrida nómina, en relación diacrónica, de los sastres vinculados a la Corona castellana entre los años de 1450 y 1615 . Por otro lado, el proteccionismo regio hacia la figura de este artesano cercano a las élites queda ostensiblemente marcado en las prebendas otorgadas a los linajes de sastres regios, como el de Fernando de Torrijos, o la actitud de la justicia en los procesos cercanos a la figura de Francisco de la Hera, sastre del Príncipe don Juan.

El hecho de que se contemplan pagos en el mismo año a distintos sastres reales da a entender que cada miembro de la familia regia solía tener el suyo propio. Mientras que los personajes más allegados al entorno de los monarcas, criadas, camareras y otros oficios de menor rango, sí que reciben de manos del tesorero o figuras afines tejidos para la confección de vestidos, que luego ellos personalmente habrían de contratar con los sastres andantes o estantes en corte o incluso con los propios sastres reales, transacción que como es lógico se escapa del alcance del registro documental de las mencionadas secciones archivísticas.

Finalmente, huelga señalar las posibilidades de esta documentación analizada para conocer en profundidad, y de la mano de fuentes históricas primarias, la historia del vestido $^{62}$, regio y el de los empleados de la corte, por contraposición a la historia del vestido ordinario de la época, determinado por otros modelos documentales del ámbito notarial, como las cartas de dote, testamentos, inventarios o cartas de aprendiz. Del mismo modo que la oportunidad de contrastar ciertos pagos efectuados en concepto de ropa y vestimenta de la época, que podrían proporcionar equivalencias útiles para bucear en la historia económica del momento.

\section{Siglas de los archivos consultados}

Archivo Histórico de la Nobleza (AHN)

Archivo General de Simancas (AGS)

Archivo de la Real Chancillería de Valladolid (ARCHV)

\section{BIBLIOGRAFÍA}

Alcega, J. de, Tratado de Geometría, Práctica y Traza, el cual trata de lo tocante al oficio de sastre..., Valladolid, Maxtor, 2009.

Alvar Ezquerra, A., El nacimiento de una capital europea: Madrid entre 1561 y 1609 , Madrid, Turner, 1989.

Baleztena Abarrategui, J., "Ordenanzas contra los sastres que tuvieren paños faltosos (1533)", Cuadernos de etnología y etnografía de navarra, 74 (1999), pp. 563-570.

Bello León, J. M., y Hernández Pérez, M. B., "Una embajada inglesa a la corte de los Reyes Católicos y su descripción en el ‘Diario' de Roger Machado”, En la España medieval, 26 (2003), pp. 167-202.

62 E. Juárez-Almendros, "Don Quijote y la moda: El legado de Carmen Bernis", Cervantes: Bulletin of the Cervantes Society of America, 24.1 (2004), pp. 137-142; J. de Alcega, Tratado de Geometría, Práctica y Traza, el cual trata de lo tocante al oficio de sastre..., Valladolid, Maxtor, 2009. 
Bouza Brey, F., "Historia de la cofradía gremial de sastres de Santiago de Compostela", Revista Compostellanum, 7 (1962), pp. 569-620.

Carretero Rubio, V., La artesanía textil y del cuero en Málaga (1487-1525), Málaga, Cedma, 1996. Comisión Internacional de Diplomática, Folia Caesaraugustana I (normas de transcripción y edición de documentos), Zaragoza, CSIC, Institución Fernando el Católico, 1984.

Domínguez Ortiz, A., "Madrid de villa a corte", en Historia y documentos notariales, Madrid, 16-2 (1992), pp. 263-279.

Falcón Pérez, M. I., "Sobre la industria del vestido en Zaragoza en el siglo XV: las ordenanzas de la cofradía de sastres, calceteros y juboneros", Aragón en la Edad Media, 12 (1995), pp. 241-266.

Fernández García, J., "La consideración social de los sastres en la tradición asturiana: (poesía popular y paremiología)", en Polledo Arias, A. C. (coord.), Fiestas Balesquida, Oviedo, 2012, pp. 89-103.

Francisco Olmos, J. M. de, "La evolución de los cambios monetarios en el reinado de Isabel la Católica según las cuentas del tesorero Gonzalo de Baeza", En la España medieval, 21 (1998), pp. 115-142.

Gestoso Pérez, J. y Fernández Gómez, M., Noticia histórico-descriptiva del antiguo pendón de la ciudad de Sevilla y de la bandera de la Hermandad de los sastres, Sevilla, Área de Cultura, 1999.

Gómez de Valenzuela, M., "La regla de la cofradía jaquesa de sastres, bajo la advocación de San Lorenzo (1602)", Argensola: Revista de CC. Sociales del Instituto de Estudios Altoaragoneses, 113 (2003), pp. 315-328.

González Arce, J. D., "De la corporación al gremio. La cofradía de sastres, jubeteros y tundidores burgaleses en 1485", Studia historica. Historia medieval, 25 (2007), pp. 191-219.

González Arce, J. D., La casa y corte del príncipe don Juan (1478-1497): economía y etiqueta en el palacio del hijo de los Reyes Católicos, Sevilla, Sociedad Española de Estudios Medievales, 2016.

González Marrero, M. del C., "Un vestido para cada ocasión: la indumentaria de la realeza bajomedieval como instrumento para la afirmación, la imitación y el boato. El ejemplo de Isabel I de Castilla", Cuadernos del CEMyR, 22 (2015), pp. 155-194.

Haldón Reina, J. F., "Aproximación histórico-artística a la antigua Hermandad de Nuestra Señora de los reyes del gremio de sastres", en Roda Peña, J. (coord.), II Semana de estudios Medievales, Nájera, 2009, pp.155-190.

Juárez-Almendros, E., "Don Quijote y la moda: El legado de Carmen Bernis", Cervantes: Bulletin of the Cervantes Society of America, 24.1 (2004), pp. 137-142.

López García, J. M., El impacto de la corte en Castilla: Madrid y su territorio en la época moderna, Madrid, siglo XXI de España, 1998.

Marchant Rivera, A., "Los sastres en los Procesos de fe del tribunal de distrito de la Inquisición de Toledo (1483-1597)", Documenta \& Instrumenta, 12 (2014), pp. 95-116.

Martínez Carreño, A., "Sastres y modistas: notas alrededor de la historia del traje en Colombia", Boletín Cultural y Bibliográfico, vol. 28, n. 28 (1991), pp. 61-76.

Mediero Velasco, M. I., "El impacto de la corte sobre la villa de Madrid", Pasea por Madrid: historia, turismo cultural y tiempo libre, 7 (2015), pp. 39-57.

Monner Sans, R., De sastres: entretenimiento paremiológica, Talleres de la Casa Jacobo Peuser, 1909.

Nieto Sánchez, J. A., "La conflictividad laboral en Madrid durante el siglo XVII: el gremio de sastres", en Actas del I Congreso de jóvenes Geógrafos e Historiadores, 1995, pp. 283-289. 
Nieto Sánchez, J. A., Artesanos y mercaderes: una historia social y económica de Madrid (1450-1850), Madrid, Fundamentos, 2006.

Nombela Rico, J. M., Auge y decadencia en la España de los Austrias: la manufactura textil de Toledo en el siglo XVI, Toledo, Ayuntamiento, 2003.

Puerta Escribano, R. de la, "Los avatares del asociacionismo de los artífices del vestir en la Valencia Moderna", en Prats, L. (coord.), Estudios en homenaje a la Profesora Teresa Puente, vol. 2, Valencia, 1996, pp. 481-495.

Puerta Escribano, R. de la, Historia del gremio de sastres y modistas en Valencia: del siglo XIII al siglo XX, Valencia, Ayuntamiento, 1997.

Puñal Fernández, T., Los artesanos de Madrid en la Edad Media (1200-1474), Madrid, UNED, 2000.

Reguera Ramírez, R., "Costureras versus sastres. También una cuestión de género", El Pajar: Cuaderno de etnografía canaria, 25 (2008), pp. 110-116.

Rodríguez Plaza, M. Á., "Ordenanzas del gremio de sastres de Plasencia. Año 1795", Revista de estudios extremeños, vol. 71, n. 2 (2015), pp. 1115-1136.

Salazar y Castro, L., Pruebas de la historia de la casa de Lara sacadas de los instrumentos por..., Madrid, Imprenta Real, 1694, p. 102.

Sanchís Llorens, R., "El offici de sastres y calcetters de Alcoy", en Primer Congreso de Historia del País Valenciano: celebrado en Valencia del 14 al 18 de abril de 1971, vol. 3, Valencia, 1976, pp. 201-208.

Vaamonde Lores, C., "La cofradía de los sastres de Betanzos", Boletín de la Real Academia Galega, 46 (1911), pp. 244-251.

Zofío Llorente, J. C., "Reproducción social y artesanos. Sastres, curtidores y artesanos de la madera madrileños en el siglo XVII", Hispania: Revista española de Historia, 71/237 (2011), pp. 87-120.

Zofío Llorente, J. C., Gremios y artesanos en Madrid, 1550-1650: la sociedad de trabajo en una ciudad cortesana preindustrial, Madrid, CSIC, 2005. 